\title{
Using Electron Backscatter Diffraction (EBSD) to Investigate Causes of Seismic Anisotropy in Earth Materials: A Case Study Using Antigorite Serpentinite
}

\author{
Sarah J. Brownlee ${ }^{1}$, Bradley R. Hacker ${ }^{2,3}$, George E. Harlow ${ }^{4}$ and Gareth Seward ${ }^{2}$ \\ 1. Wayne State University, Department of Geology, Detroit, MI, USA. \\ 2. University of California, Santa Barbara, Department of Earth Science, Santa Barbara, CA, USA. \\ 3. University of California, Santa Barbara, Earth Research Institute, Santa Barbara, CA, USA. \\ 4. American Museum of Natural History, Department of Earth Science, New York, NY, USA.
}

Seismic anisotropy is the directional dependence of seismic wave velocity, and can have a number of causes in Earth materials, such as oriented cracks and fractures, and crystallographic-preferred orientation of minerals in rocks. With a better understanding of the material causes of seismic anisotropy, and the deformation processes that produce them, we can better interpret seismic data both in terms of the active deformation mechanisms and the composition of the material.

This study focuses on the crystallographic preferred orientation (CPO) of minerals in rocks as a cause of seismic anisotropy. Mineral CPOs develop as a result of deformation and are dependent on many factors, including overall mineralogy of the rock, temperature, deformation history, and strain geometry. The geometry and strength of the resulting CPO exerts a strong control on the elastic properties of the aggregate material. We use electron backscatter diffraction (EBSD) to measure mineral CPOs in combination with published single crystal elastic constants to calculate the anisotropic elastic properties of naturally deformed Earth materials. We applied this technique to samples of serpentinite mélange from the Guatemala Suture Zone in central Guatemala [1] in order to study the causes of seismic anisotropy in the mantle wedge of a subduction zone.

Seismic anisotropy in the mantle is often used to infer mantle flow directions, but anisotropy in the tip of a subduction zone mantle wedge is likely to be affected by mantle alteration (e.g., hydration of olivine). Understanding the mechanisms responsible for anisotropy in subduction zones helps to provide a link between seismic observations and the processes occurring in subduction zones. In particular, seismic experiments have observed trench-parallel shear wave splitting at a number of subduction zones, but the causes of this are not yet well understood. Kneller et al. [2] suggested that a type-B olivine CPO in the tip of a mantle wedge can explain some, but not all, of the observed magnitude of trench-parallel shearwave splitting, and suggested that the growth of antigorite might explain the remainder. We investigate the potential contribution of antigorite to subduction zone anisotropy by measuring the CPO of antigorite in 7 serpentinites from central Guatemala using EBSD and calculating the seismic properties using the single-crystal elastic constants of antigorite from Bezacier et al. [3].

Because antigorite can be quite difficult to prepare for EBSD, we polished each sample by hand in a stepwise fashion. We achieved the highest quality diffraction patterns when the samples were measured uncoated in low vacuum (70 Pa), using a working distance of 10-15 mm, and accelerating voltage of 20 $\mathrm{kV}$. Each sample was mapped twice, once with a fine step size $(1-2 \mu \mathrm{m})$ to image the grain size and microstructure of a small region $\left(1 \mathrm{~mm}^{2}\right)$, and once with a coarse step size $(50-100 \mu \mathrm{m})$ to obtain 1point-per-grain measurements to characterize the antigorite CPO over most of each thin section (1-3 $\mathrm{cm}^{2}$ ). Fine-scale band contrast images show a range of microstructures, from slightly elongated plates to submicron needles. Our results show two types of antigorite $\mathrm{CPO}$ - one related to deformation and one 
related to growth of antigorite - which result in calculated anisotropies of 6-28\% in $V_{P}$ and 5-33\% in $V_{S}$. Depending on the distribution of antigorite within a subduction zone mantle wedge this anisotropy is sufficient to explain the discrepancy between observed seismic anisotropy and that predicted by type-B olivine CPO. [4]

[1] Harlow, G. E., et al., Abs. Ann. Meeting, Geological Society of America, 42(5) (2010), p. 679.

[2] Kneller, E. A., et al. Earth and Planetary Science Letters 268 (2008), p. 268.

[3] Bezacier, L., et al. Earth and Planetary Science Letters 289 (2010), p. 198.

[4] The authors acknowledge funding from NSF grants EAR-0607775, EAR-0745588, EAR-0309320, and EAR-1119403. This work is in review with Earth and Planetary Science Letters.

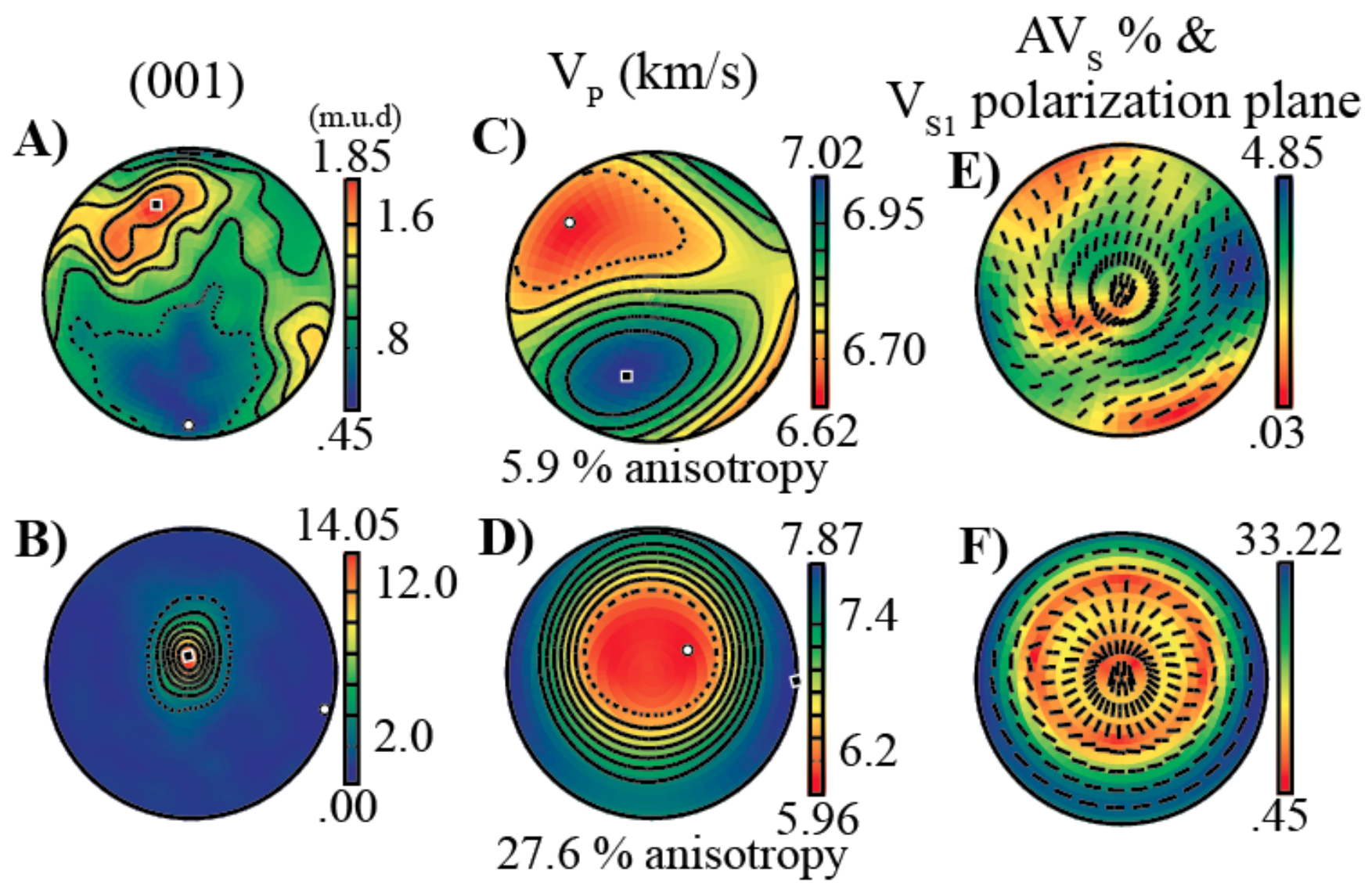

Figure 1. Pole figures of (001) show two kinds of antigorite CPO, one related to growth of antigorite (A), and one related to deformation (B). Contours are multiples of uniform distribution (m.u.d), a measure of CPO strength. The different CPOs produce very different anisotropic elastic properties. Stereonets of $V_{P}$ are shown in $C$ ) and $D$ ), and shear wave anisotropy in $E$ ) and F). Shear wave anisotropy $\left(A V_{S}\right)$ is the difference between $V_{S 1}$ and $V_{S 2}$ in a particular propagation direction, divided by the median $\mathrm{V}_{\mathrm{S} 1}$, and is related to the predicted magnitude of shear wave splitting for that specific propagation direction. The direction of the fast shear wave polarization plane is also shown, and is related to shear wave splitting direction. 